\title{
Stage at Diagnosis and Delay in Seeking Medical Care Among Women With Breast Cancer, Delhi, India
}

\author{
Sedigheh Pakseresht ${ }^{1}$; Gopal Krishna Ingle ${ }^{2}$; Suneela Garg ${ }^{2}$; Nahid Sarafraz ${ }^{3, *}$ \\ ${ }_{1}^{1}$ Reproductive Health Research Center, Department of Obstetrics, Guilan University of Medical Sciences, Rasht, IR Iran \\ 2 Department of Community Medicine, Maulana Azad Medical College, New Delhi, India \\ 3 Department of Midwifery, Kashan University of Medical Sciences, Kashan, IR Iran \\ *Corresponding Author: Nahid Sarafraz, Department of Midwifery, Kashan University of Medical Sciences, Kashan, IR Iran. Tel:+98-9132614866, Fax:+98-3615556633, E-mail:nsarafraz@
} yahoo.com

Received: September 19, 2013; Revised: September 6, 2014; Accepted: October 18, 2014

Background: Patients with cancer often delay seeking medical advice in developing countries. It can adversely influence the outcome of disease.

Objectives:The present study was performed to determine the stage at diagnosis and delay in seeking medical care among women with breast cancer in Delhi, India.

Patients and Methods: This was a cross-sectional study based on a census (case series) approach to reach all women (172) diagnosed with primary breast cancer "detected in surgery Out Patient Department (OPD) from January 2007 to December 2009" at Lok Nayak Hospital, Delhi, India. Patients were interviewed using a self-structure questionnaire. Seeking behavior variables were awareness of problem, first consultation, followed physician's advice, detection of problem, system of medicine and gap between knowing the problem and consultation (patient delay). Statistical Analysis was performed using the Microsoft SPSS-pc version 14.0 statistical program. The analytic methods were used (mean, standard deviation, $\mathrm{X}^{2}$, Fisher's Exact Test, K-S, Kruskal-Wallis) for variables. All statistical tests were performed at a significance level of $5 \%(\mathrm{P}<0.05)$.

Results: the mean age of women was 46.99 years. $38.4 \%$ of women were $\leq 40$ years. $61 \%$ of women were in stage IV of cancer at the time of diagnosis. The mean duration of gap between knowing the problem and consulting a physician (patients delay) was 10.90 months. There was no significant association between stage of cancer and consultation gap. A significant association was found between the stage of breast cancer and income; women with lower income had a higher stage of breast cancer $(\mathrm{P}<005)$.

Conclusions:A significant association was found between ages of women with their delays in consultation. Delay is still prevalentamongst women with breast cancer. It seems necessary to design educating programs for women in both clinical and community settings, about breast cancer and early detection practices.

Keywords:Breast Neoplasm; Patient Acceptance of Health Care; Women

\section{Background}

Patients with cancer often delay seeking medical advice in developing countries. It can adversely influence the outcome of disease $(1,2)$. Around $80 \%$ of patients with breast cancer reported to refer to health care centers in late stage when the disease had become incurable (3). Few population-based studies have been conducted on patients with breast cancer to understand their health seeking behaviors. In developing countries, most patients with breast cancer continue to be diagnosed at a relatively late stage, and locally advanced cancers constitute over $50 \%$ of all patients (4). It has been observed that breast cancer is frequently diagnosed at later stage among patients with lower income (48\%) and educational status contributing to poorer survival $(5,6)$. Patient delay is defined as the period from the first onset of symptoms to the first medical consultation (as the time gap of $>3$ months) (7). Despite extensive measures to promote early detection of breast cancer, an estimated
$20 \%-30 \%$ of women would wait at least three months before seeking help for breast cancer symptoms. Women with delayed presentation (more than three months) often have larger tumors and poorer long-term survival $(8,9)$. The proportion of women who seek consultation after three months ranges from $14 \%$ to $19 \%$ in developed countries, while other reports from developing countries found delay as high as $67 \%$ in Peru and $42 \%$ in Iran (6). In India, Only $15 \%$ of patients with cancer attended for medical assistance in localized stage of disease. There is always delay between the first symptoms and time of diagnosis and initiation of treatment in women with symptomatic breast cancer. This delay results in significant worsening of the disease process $(4,8,10)$. Delays in seeking help for symptoms have been associated with poorer outcome in patients with breast cancer (11). Reducing treatment delay improves outcomes in breast cancer. Delay in treatment results in significant worsening of the disease pro-

Copyright (C) 2014, Iranian Red Crescent Medical Journal. This is an open-access article distributed under the terms of the Creative Commons Attribution-NonCommercial 4.0 International License (http://creativecommons.org/licenses/by-nc/4.0/) which permits copy and redistribute the material just in noncommercial usages, provided the original work is properly cited. 
cess (12). A variety of psychosocial and cultural factors predispose women to delay or avoidance of screening for breast cancer symptoms at early stages when treatment is most likely to be successful (13). The delay in diagnosis and treatment of breast cancer remains a serious problem (14-16). Therefore, the present study was performed to determine the stage at diagnosis and delay in seeking medical care among women with breast cancer. Consequently, the results of this study can help policy makers to design healthcare programs for early detection.

\section{Objectives}

The present study was performed to determine stage at diagnosis and delay in seeking medical care among women with breast cancer in Delhi, India.

\section{Patients and Methods}

\subsection{Study Design and Sample}

This was a cross-sectional study, based on a census (case series) approach to reach all women (172) diagnosed with primary breast cancer "detected in surgery Out Patient Department (OPD) from January 2007 to December 2009" who had not started cancer treatment and admitted to surgery ward located in Lok Nayak Hospital, New Delhi, India. This is a 1600 bed hospital affiliated to a medical college in India, which provides services to more than one million patients per year from Delhi and neighboring states (12). The diagnosis of breast cancer was made by the surgeon on the basis of physical examination and fine needle aspiration cytology (FNAC)/core biopsy report. Eligible women were those with breast cancer, determined by clinical and paraclinical investigations (having documented). Women were eligible for selection in this study and included in analyses if they had a primary detection regarding breast cancer. Therefore, to facilitate medical record checking, women able to answer the questionnaire and those willing to participate were included. Women with a history or recurrence of breast cancer, having metastasis at the time of diagnosis, reconstructive surgeries, severe psychiatric illness or any other cancer were excluded from the study. After the diagnosis, an informed consent was obtained from each patient and interviewed using pretested, pre-structured questionnaire. The questionnaire consisted of two parts as: Part I, sociodemographic profile (such as age, marital status, occupation, literacy, religion, number of children and place of residence (urban/rural); Part II, seeking behaviors variables (awareness of problem, first consultation, following physician's advice, detection of problem, system of medicine, gap between knowing the problem and consultation (patient delay) and stage at diagnosis). Prepared questionnaire by the authors was validates by 12 people of medical college members. A pilot study was performed on 20 patients to adjust questionnaire for ratability before performing the main investigation. It was confirmed by Cronbach's alpha of $82 \%$. The investigator asked help of a trained person able to communicate in local language with women. All study subjects were explained and informed about the purpose of study. Subjects received standard treatment if refused to participate. There was no coercion at any stage and subjects could withdraw at any stage of study. Confidentiality of the information provided by subjects was protected. Questionnaires were completed during patient's bedding in surgery ward and after checking confirmed cancer report.

Women were asked to recall the gap between knowing the problem and their first medical consultation due to breast cancer. This date was used as a reference for questions about whether she perceived symptoms and awareness of problem, the time symptoms were present before the first consultation and socioeconomic factors at the first medical consultation. Type of system of medicine (Allopathy, Ayurveda and Homeopathy) for the first medical consultation was also established. In symptomatic women, patient delay was defined as the time elapsed between symptoms onset and the first medical consultation. Reasons for delay were recorded for patients waited more than three months after symptoms for the first consultation. Each medical record was reviewed to extract information about tumor characteristics. Clinical staging of the tumor according to the tumor, nodal, and metastasis (TNM) classification of malignant tumors was recorded. From all women who came to the hospital in the two years $(n=259200), 768(0.29 \%)$ patients with cancer came to the hospital. A total of 768 patients with cancer were recruited, and 231 (30\%) of these patients were screened as breast cancer. 179 of these women were eligible to be included; of 179 women 172 completed questionnaires. Seven women were lost (3 women were not bedded and 4 women not approached for the study). This study was as a part of PhD thesis approved by the Research Ethics Committee of Maulana Azad Medical College, New Delhi, India in 6 January 2006.

\subsection{Statistical Analysis}

Statistical Analysis was performed using the Microsoft SPSS-pc version 14.0 statistical program. All statistical tests were performed at a significance level of 5\% ( $\mathrm{P}<$ 0.05). The authors used analytic methods (mean, standard deviation, $\mathrm{X}^{2}$, Fisher's Exact Test, K-S, Kruskal-Wallis) for variables. For simple descriptions, all variables were treated as categorical analyzed as a quantitative variable. Frequencies were presented as absolute values as percentage. Associations between categorical variables and patient delay were assessed using contingency tables and Chi-square or Fisher exact tests. Strength of association was measured using 95\% confidence intervals. KruskalWallis test was used to estimate the association between patient's literacy and monthly family income with stage of breast cancer as the main outcome variable. 
Figure 1. Distribution of Subjects According to Family Income ( $\$ 1=50$ Rs).

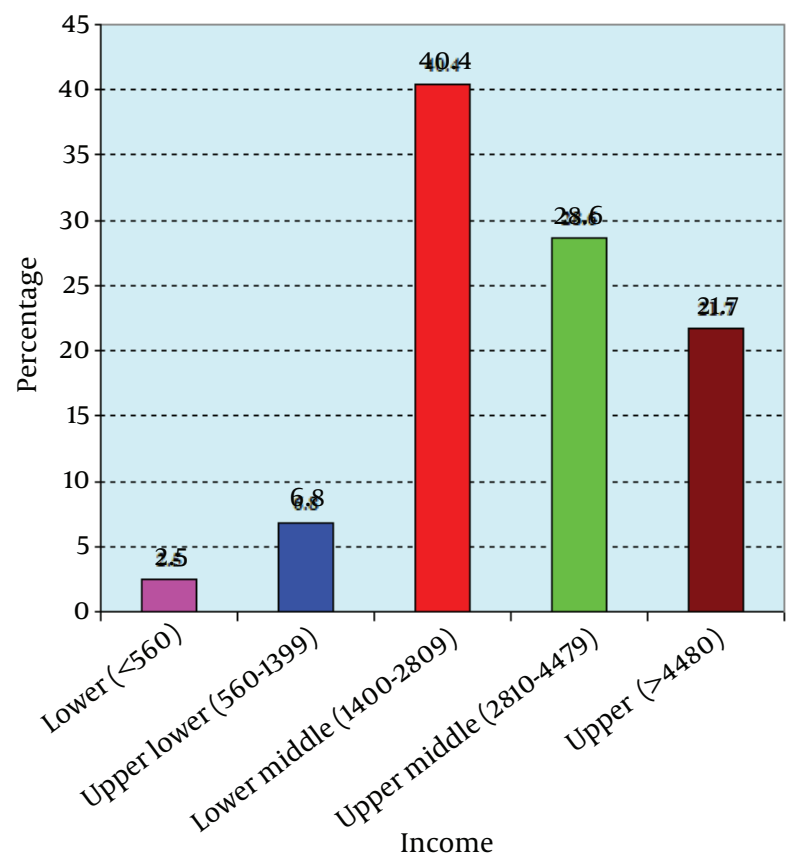

* As per income parameter of Modified Mahajan and Gupta Classification based on per capita family income per month ( $\$ 1=50 \mathrm{Rs})$; $\mathrm{RS}=$ Rupees is currency in India; ** 11 subjects did not reveal their income.

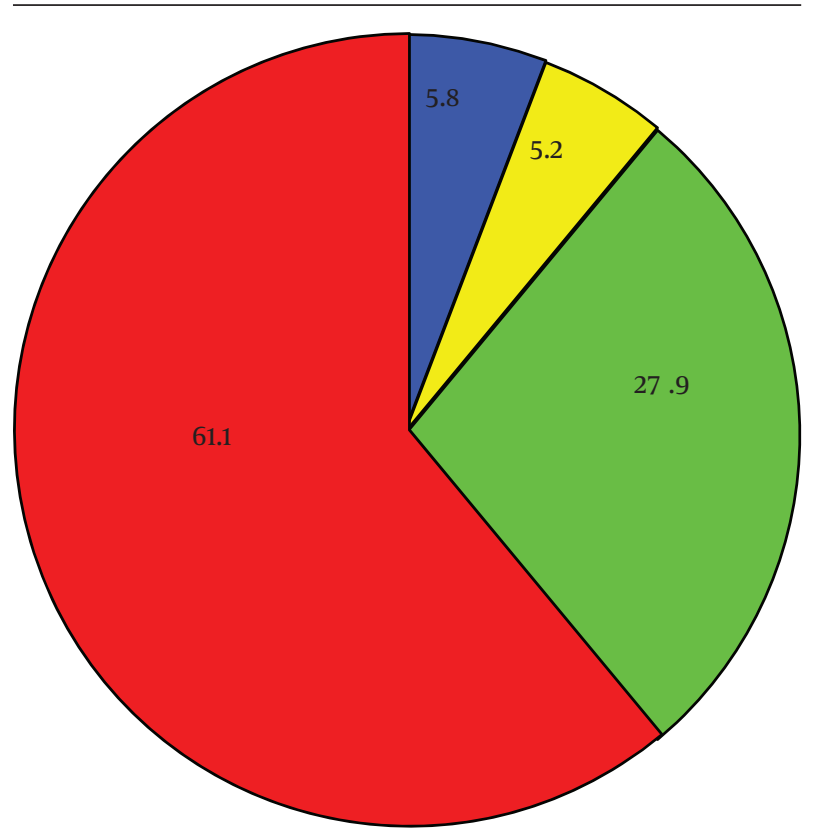

Stage I Stage III Stage IIII Stage IV

Figure 2. Stage of Breast Cancer at the Time of Diagnosis in Subjects

\section{Results}

The mean age of patients was 46.99 years ( $S D \pm 12.6$ ) ranging from 25 to 80 years. Age distribution showed that $38.4 \%$ of the women were $\leq 40$ years, $20.9 \%$ between 40 49 years, $16.9 \%$ between $50-59$ years and $23.8 \%>60$ years. In total, $70.3 \%$ of women were living with their spouse, while $29.7 \%$ women were not living with their spouse including widowed (27.3\%), divorcee (1.2\%) and unmarried (1.2\%) ones. $95.3 \%$ of women were housewives. $62.2 \%$ of women were illiterate. $68 \%$ of women were Hindus, while Muslims constituted the second largest group. Only one patient was a Sikh and one Christian. Besides, 52.9\% originally belonged to urban areas and 54.1\% from states other than Delhi. 70.9\% of the women were aware of the fact that they have breast cancer and $98.8 \%$ of women detected their problems by breast-self-examination. $71.5 \%$ of women sought treatment from a physician in allopathic system of medicine. The mean duration of gap between knowing the problem and consulting a physician was 10.9 months $(S D \pm 20.19$, median $=5$ months, range $0-237$ months) and $38.4 \%$ of women sought consultation with a physician within three months of the onset of symptoms. In total, $62.2 \%$ had completely followed the advice given by physician consulted first until the time of diagnosis at Lok Nayak Hospital. According to income, most women (40.4\%) belonged to lower middle groups (Figure 1). Stage of breast cancer at the time of diagnosis was IV in $61 \%$ of women (Figure 2).

Table 1 shows the association of women literacy and the stage of breast cancer. There was no normal distribution in literacy, so Kruskal-Wallis was used to compare literacy and stages of breast cancer, which revealed a significant difference in four stages $(\mathrm{P}<0.05)$. The mean years of schooling decreased with advanced stages. We categorized the literacy status of women as an illiterate (having no formal or informal schooling) and literate (having formal education). Awareness of breast cancer was higher (80\%) among literate women than illiterate ones (65.4\%). Besides, 5.6\% of the illiterate women first consulted a quack, whereas none of the literate women did. 72.3\% of literate women completely followed physician advice; whereas, only $56.1 \%$ of the illiterate women did. Among literate women, $76.9 \%$ used allopathy, $13.8 \%$ ayurveda and 9.2\% homeopathy; whereas, among illiterate women, $68.2 \%$ used allopathy. Gap of $<3$ months between knowing the problem and consultation was $41.5 \%$ among the literate women versus $36.4 \%$ among illiterate ones. Gap between knowing the problem and consultation was lower among literate women than illiterate ones. The analysis revealed a statistically significant association between patient's literacy and awareness of problem, first consultation, and compliance with physician advice $(\mathrm{P}<$ $0.05)$, but the association between patient's literacy and the method of detection of their problem, system of medicine consulted and gap between knowing the problem and consultation was not significant. Among the women 
with gap of $<3$ months between knowing the problem and consultation, $25.8 \%$ of women were in stage III and $62.1 \%$ of them were in stage IV. A similar pattern was observed among women with gap of 3-10 months and $>10$ months. There was no significant association between stage of cancer and consultation gap. Table 2 revealed gaps between knowing the problem and consultation and demographic variables. No demographic variable had a significant association with gap between knowing the problem and consultation except for age $(\mathrm{P}<0.05)$. Figure 3 shows gaps between knowing the problem and consultation (patient delay) and age of the subjects. Table 3 shows a significant association between the stage of breast cancer and income (median of income was 3000 and IQR was 2100 Rupees). There was no normal distribution in income, so Kruskal-Wallis as a nonparametric test was used to compare income and stages of breast cancer, which a significant difference was found in four stages ( $P$ $<0.02)$. Post Hoc test showed a significant different between the first and fourth stages of cancer as well, indicating that women with lower income had higher stage of breast cancer $(\mathrm{P}<0.02)$.

\begin{tabular}{llll}
\hline Table 1. Patient's Literacy and Stage of Breast Cancer $(\mathrm{n}=172)^{\mathrm{a}}$ \\
\hline Stage & \multicolumn{4}{l}{ Patient's Literacy, Years of Schooling } \\
\cline { 2 - 4 } & $\mathbf{N}$ & Mean \pm SD & PValue \\
\hline Stage I & 10 & $6.50 \pm 6.32$ & 0.05 \\
Stage II & 9 & $5.67 \pm 5.91$ & 0.05 \\
Stage III & 48 & $3.50 \pm 4.95$ & 0.05 \\
Stage IV & 105 & $2.85 \pm 4.30$ & 0.05 \\
\hline
\end{tabular}

a One way ANOVA, $\mathrm{F}=2.45, \mathrm{DF}=3$.

Table 2. Gap Between Knowing the Problem and Consultation and Demographic Variables $(\mathrm{n}=172)^{\mathrm{a}}$

\begin{tabular}{|c|c|c|c|c|c|}
\hline \multirow{2}{*}{$\begin{array}{l}\text { Demographic } \\
\text { Variables }\end{array}$} & \multicolumn{5}{|c|}{ Gap between Knowing the Problem and Consultation } \\
\hline & $<3$ Months $(\mathrm{n}=66)$ & 3-10 Months $(n=49)$ & $>10$ Months $(n=57)$ & PValue & Test \\
\hline Marital status & & & & 0.24 & $\mathrm{X}^{2}$ value $=2.79 ; \mathrm{df}=2$ \\
\hline $\begin{array}{l}\text { Living without } \\
\text { spouse }\end{array}$ & $15(22.7)$ & $18(36.7)$ & $18(31.6)$ & & \\
\hline $\begin{array}{l}\text { Living with } \\
\text { spouse }\end{array}$ & $51(77.3)$ & $31(63.3)$ & $39(68.4)$ & & \\
\hline Literacy & & & & 0.16 & $\mathrm{X}^{2}$ value $=3.62 ; \mathrm{df}=2$ \\
\hline Illiterate & $39(59.1)$ & $27(55.1)$ & $41(71.9)$ & & \\
\hline Literate & $27(40.9)$ & $22(44.9)$ & $16(28.1)$ & & \\
\hline Occupation & & & & 0.30 & Fisher's exact test \\
\hline Housewives & $63(95.5)$ & $49(100)$ & $52(91.2)$ & & \\
\hline Others & $3(4.5)$ & $0(0)$ & $5(8.8)$ & & \\
\hline Age, $y$ & & & & 0.05 & $\mathrm{X}^{2}$ Value $=12.24 ; \mathrm{df}=6$ \\
\hline$<40$ & $24(36.4)$ & $25(51)$ & $17(29.8)$ & & \\
\hline $40-49$ & $16(24.2)$ & $11(22.4)$ & $9(15.8)$ & & \\
\hline $50-59$ & $11(16.7)$ & $8(16.3)$ & $10(17.5)$ & & \\
\hline $60<$ & $15(22.7)$ & $5(10.2)$ & $21(36.8)$ & & \\
\hline Place of residence & & & & 0.14 & $\mathrm{X}^{2}$ Value $=3.84 ; \mathrm{df}=2$ \\
\hline Urban & $41(62.1)$ & $22(44.9)$ & $28(49.1)$ & & \\
\hline Rural & $25(37.9)$ & $27(55.1)$ & $29(50.9)$ & & \\
\hline State of residence & & & & 0.69 & $\mathrm{X}^{2}$ Value $=0.74 ; \mathrm{df}=2$ \\
\hline Delhi & $32(48.5)$ & $20(40.8)$ & $27(47.4)$ & & \\
\hline Other states & $34(51.5)$ & $29(59.2)$ & $30(52.6)$ & & \\
\hline $\begin{array}{l}\text { Number of } \\
\text { children }\end{array}$ & & & & 0.07 & $\mathrm{X}^{2}$ Value $=8.52 ; \mathrm{df}=4$ \\
\hline No Children ${ }^{\mathrm{b}}$ & $2(3.0)$ & $1(2.0)$ & $4(7.0)$ & & \\
\hline 1-2 Children ${ }^{\mathrm{b}}$ & $17(25.8)$ & $10(20.4)$ & $21(36.8)$ & & \\
\hline 3-4 Children & $36(54.5)$ & $26(53.1)$ & $19(33.3)$ & & \\
\hline$>4$ Children & $11(16.7)$ & $12(24.5)$ & $13(22.8)$ & & \\
\hline
\end{tabular}


$\mathrm{a}$ Data are presented as No. (\%).
$\mathrm{b}$ No children and 1-2 children categories merged for the analysis.

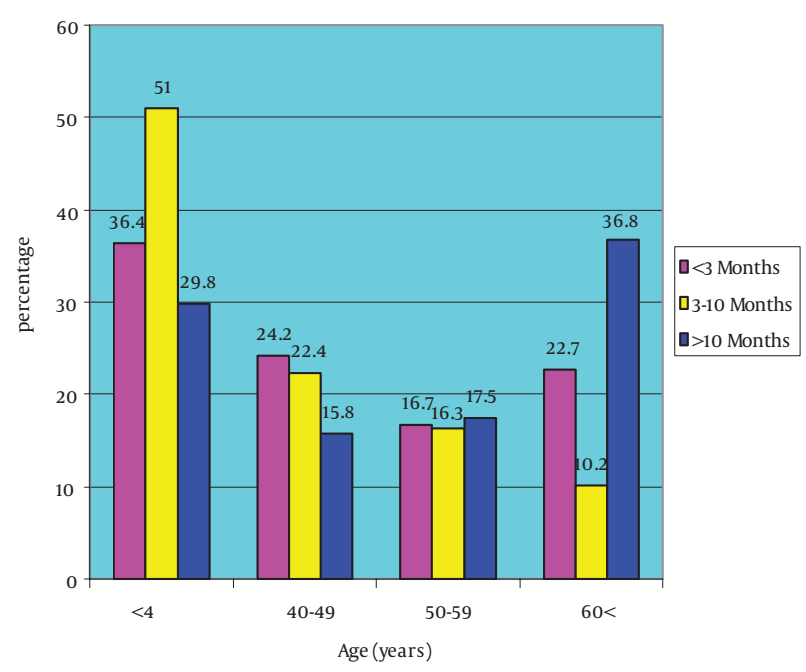

Figure 3. Gap Between Knowing the Problem and Consultation (Patient Delay) and Age of the Subjects

Table 3. Stage of Cancer and Monthly Family Income (Rs) Among Subjects $(\mathrm{n}=161)^{\mathrm{a}}$

\begin{tabular}{lccc}
\hline Stage & \multicolumn{3}{c}{ Monthly Family Income, Rs } \\
\cline { 2 - 4 } & $\mathbf{N}$ & Mean \pm SD & P Value \\
\hline Stage I & 10 & $5800 \pm 3994.44$ & 0.02 \\
Stage II & 7 & $3285 \pm 1976.05$ & 0.02 \\
Stage III & 46 & $3534 \pm 3360.31$ & 0.02 \\
Stage IV & 98 & $3092 \pm 2534.56$ & 0.02 \\
Total & 161 & $3396 \pm 2921.9$ & 0.02 \\
\hline
\end{tabular}

$\mathrm{a}_{11 \text { subjects did not reveal their income. }}$

\section{Discussion}

The mean age of women was 46.99 years. Some studies reported the mean age of 47-57- $48.2 \pm 10.19$ years $(1,17,18)$ for women with breast cancer. An author reported that the incidence rates in India began to rise in the early thirties with a peak at 50-64 years (3). In this study, $38.4 \%$ of women were $\leq 40$ years. While, other studies showed the highest prevalent age group as 40-49 years (17-19). Another study reported an association between younger age $(\mathrm{P}<0.05)$ and delay for medical consultation (20). A study showed that older women are at a greater risk of developing breast cancer, also more likely to delay their presentation (21). The reasons are not entirely clear but some could be lower life expectancy, under-diagnosis and under-reporting from the population. In this study, 70.9\% of women were aware that they have breast cancer. Other studies showed similar finding (70-78.1\%) $(4,12,22)$. This result is consistent with the results of other researchers.
In this study, $98.8 \%$ of women detected their problems by self-examination. Another study reported that most women (85\%) discovered the lump accidentally (2). Nevertheless, a study reported that only $44 \%$ recognized their disease by self-examination (12). In this study, 52\% of women originally belonged to urban areas. As per 2001 national census, $72.2 \%$ of Indian population are living in rural areas (23). Another study showed that $60 \%$ of women lived in rural areas (24). A study showed that notable differences were observed between rural and urban areas in India (25). These differences might be due to location of hospital in urban area. In this study, $68 \%$ of women were Hindus. At the census national level, as per 1028 million population, 828 million (80.5\%) mentioned their religion as Hindus followed by 138 million (13.4\%) as Muslim (23). A study reported that most (64.3\%) women were Hindu and 14.1\% Muslim (26); these differences might be due to geographical variation. In the current study, 95.3\% of women were housewives. A similar study revealed $75.7-85 \%$ women as unemployed (12); these could be due to their poor socioeconomic background and lack of education. Most women (40.4\%) belonged to lower middle class among per capita of per month income (Rs 1400-2809). A similar investigation showed that women with lower income had a higher stage of breast cancer (27), and 70.3\% of women were living with their spouse. A similar finding was reported in another study (27). In total, $62.2 \%$ of women were illiterate, while a study reported only $4.6 \%$ of women (28) and $42.2 \%$ in another study (12). This difference might be due to different levels of education in different places. In the current study, $71.5 \%$ of women sought treatment from a physician belonging to allopathic system of medicine. In contrast, the most common used system of medicine was homeopathy (70\%) in another study (29). Another study reported that most women sought the treatment from traditional medicine (15). In this study, diagnosis was made with a gap between knowing the problem and consultation and only $38.4 \%$ of women sought consultation with a physician within three months of the onset of symptoms. A study showed a mean of three months to seek medical advice after recognizing the first symptom with a delay of 1-72 months (12). A study reported that in $19 \%$ of women, delay was 12 weeks or more (16). A study reported that mean patient delay was $32.2 \pm 63.8$ weeks (7). Some studies reported that $90 \%$ of women delayed $\leq 12$ weeks to consult a physician $(12,14,15)$. A systematic overview showed that delays of 3-6 months were clearly associated with increased tumor size, advance in disease stage and poorer long-term prognosis. One study confirmed that survival was worse with delays of more than 12 weeks $(30,31)$. The observed variations might be due to sociodemographic factors of women or location of hospital and places of living or difference in sample characteristics, differences in delay 
interval studied or variations in the definition of delay.

In the present study, $27.9 \%$ were in stage III and $61 \%$ in stage IV of breast cancer. A study reported values of $22 \%$ and $6.8 \%$ for stage III and IV, respectively. Moreover, stage II was found in $57 \%$ and stage III in $25 \%$ of the cases at diagnosis (32). Another study showed values of $7.8 \%$ for stage I and $47.6 \%$ for stage IIb in women with breast cancer (2). Another investigation found $50 \%$ to $60 \%$ in late stages (III+IV) (25). A Study reported that $86.4 \%$ of women were diagnosed with a tumor size larger than $2 \mathrm{~cm}$ in New Delhi (26). In contrast, $15 \%$ of breast cancers are diagnosed at late stage (25). Furthermore, $16 \%$ of women had stage I, 74\% stage II (25) and 52-60\% stage I (31). Another author found that about $60-70 \%$ of women presented with early stage (stages 1-2), while $30-40 \%$ presented with late breast cancer (stages 3-4) (32). A study showed that most patients with breast cancer are diagnosed at a relatively late stage in India, Malaysia and Hong Kong and developing countries (4). Early breast cancer (EBC) constitutes only $30 \%$ of the breast cancer cases seen at regional cancer centers in India, whereas it constitutes $60-70 \%$ of cases in the developed world. Delay in seeking medical advice is considered as one of the reasons for increased cancer mortality in developing countries $(6,12)$. Better socioeconomic conditions, health awareness and availability of breast cancer screening in developed Asian countries are major causes of a favorable clinical picture and outcomes in these countries. It can be due to poorer knowledge about early breast cancer detection. In conclusion, findings of this study are consistent with some other studies in developing countries. This is in contrast to what reported from developed countries. In developed countries, the use of routine screening mammography has led to the detection of very early lesions. As mammography facilities are not widely available in India and there is no nationwide breast-screening program, early detection of breast cancer is not possible. Delay in early detection could be due to differences in sociodemographic and cultural factors, a strong belief in traditional medicine, negative perception of disease, poverty and poor education and coupled with fear and denial. Subsequently, as a recommendation, education is needed to increase knowledge for early detection of breast cancer. Changes in behavior of women and physicians are needed to increase the use of breast self-examination, clinical breast examination by a health care professional and mammographic screening. In addition, authors recommend to investigate the reasons why women delay their presentation with breast cancer. Although, this hospital is a large and 1600 bedded hospital providing services to more than one million patients annually from Delhi and neighboring states and affiliated to the most known medical college in Delhi. Our findings were indicative of women admitted to this hospital and generalization of data to other centers requires caution. The number of non-participating centers due to our study design may be related to a selection bias. In this case, a specialized cancer care center provides care for populations with different number. Moreover, women were asked to recall the month and year of the first time they perceived signs and symptoms due to breast cancer, which could yield a recall bias. We believe that our results could be generalized to patients with breast cancer treated in Delhi subsidized.

\section{Acknowledgements}

The authors duly acknowledge the contribution and help of Surgery Department, PSM Department and Department of Radiotherapy, Maulana Azad Medical College, Lok Nayak Hospital, New Delhi in preparation of this paper.

\section{Authors' Contributions}

Study concept and design: Sedigheh Pakseresht, Ingle and Nahid sarafraz; analysis and interpretation of data: Garg and Sedigheh Pakseresht; drafting of the manuscript: Sedigheh Pakseresht; critical revision of the manuscript for important intellectual content: Ingle, Garg and Sedigheh Pakseresht; statistical analysis: Ingle and Garg. Nahid sarafraz wrote the manuscript.

\section{Funding/Support}

This study was supported by Surgery Department, PSM Department and Department of Radiotherapy, Maulana Azad Medical College, Lok Nayak Hospital, New Delhi.

\section{References}

1. Meechan G, Collins J, Petrie K. Delay in seeking medical care for self-detected breast symptoms in New Zealand women. $N$ Z Med J. 2002;115(1166):U257.

2. Malik IA, Gopalan S. Use of CAM results in delay in seeking medical advice for breast cancer. EurJ Epidemiol. 2003;18(8):817-22.

3. Raina V, Bhutani M, Bedi R, Sharma A, Deo SV, Shukla NK, et al. Clinical features and prognostic factors of early breast cancer at a major cancer center in North India. Indian $J$ Cancer. 2005;42(1):40-5.

4. Agarwal G, Pradeep PV, Aggarwal V, Yip CH, Cheung PS. Spectrum of breast cancer in Asian women. World J Surg. 2007;31(5):1031-40

5. Burgess CC, Potts HW, Hamed H, Bish AM, Hunter MS, Richards MA, et al. Why do older women delay presentation with breast cancer symptoms? Psychooncology. 2006;15(11):962-8.

6. Pineros M, Sanchez R, Cendales R, Perry F, Ocampo R. Patient delay among Colombian women with breast cancer. Salud Publica Mex. 2009;51(5):372-80.

7. Brzozowska A, Duma D, Mazurkiewicz T, Brzozowski W, Mazurkiewicz M. [Reasons for delay in treatment of breast cancer detected due to breast self-examination in women from the Lubelskie region]. Ginekol Pol. 2014;85(1):14-7.

8. Heisey R, Clemons M, Granek L, Fergus K, Hum S, Lord B, et al Health care strategies to promote earlier presentation of symptomatic breast cancer: perspectives of women and family physicians. Curr Oncol. 2011;18(5):e227-37.

9. Unger-Saldana K, Infante-Castaneda CB. Breast cancer delay: a grounded model of help-seeking behaviour. Soc Sci Med. 2011;72(7):1096-104.

10. O'Mahony M, Hegarty J, McCarthy G. Women's help seeking behaviour for self discovered breast cancer symptoms. Eur J Oncol Nurs. 2011;15(5):410-8.

11. El Saghir NS, Shamseddine AI, Geara F, Bikhazi K, Rahal B, Salem $\mathrm{ZM}$, et al. Age distribution of breast cancer in Lebanon: increased 
percentages and age adjusted incidence rates of younger-aged groups at presentation. J Med Liban. 2002;50(1-2):3-9.

12. El-Shinawi M, Youssef A, Alsara M, Aly MK, Mostafa M, Yehia A, et al. Assessing the level of breast cancer awareness among recently diagnosed patients in Ain Shams University Hospital. Breast. 2013;22(6):1210-4.

13. Ahmadian M, Samah AA. Application of health behavior theories to breast cancer screening among Asian women. Asian Pac J Cancer Prev. 2013;14(7):4005-13.

14. Jassem J, Ozmen V, Bacanu F, Drobniene M, Eglitis J, Lakshmaiah $\mathrm{KC}$, et al. Delays in diagnosis and treatment of breast cancer: a multinational analysis. EurJ Public Health. 2014;24(5):761-7.

15. Arndt V, Sturmer T, Stegmaier C, Ziegler H, Dhom G, Brenner H. Patient delay and stage of diagnosis among breast cancer patients in Germany - a population based study. Br J Cancer 2002;86(7):1034-40.

16. Kothari A, Fentiman IS.22. Diagnostic delays in breast cancer and impact on survival. Int J Clin Pract. 2003;57(3):200-3.

17. Saxena S, Chakraborty A, Kaushal M, Kotwal S, Bhatanager D, Mohil RS, et al. Contribution of germline BRCA1 and BRCA2 sequence alterations to breast cancer in Northern India. BMC Med Genet. 2006;7:75.

18. Pinto BM, Rabin C, Abdow S, Papandonatos GD. A pilot study on disseminating physical activity promotion among cancer survivors: a brief report. Psychooncology. 2008;17(5):517-21.

19. Palmer JR, Adams-Campbell LL, Boggs DA, Wise LA, Rosenberg L. A prospective study of body size and breast cancer in black women. Cancer Epidemiol Biomarkers Prev. 2007;16(9):1795-802.

20. Friedman LC, Kalidas M, Elledge R, Dulay MF, Romero C, Chang $\mathrm{J}$, et al. Medical and psychosocial predictors of delay in seeking medical consultation for breast symptoms in women in a public sector setting. J Behav Med. 2006;29(4):327-34.

21. Earle C, Coyle D, Wells G, Papadimitropoulos E. . A needs based assessment of breast cancer in Canada: the economic burden of illness. Annual Meeting of the International Society of Technology Assessment in Health Care. 1999.
22. Pohls UG, Fasching PA, Beck H, Kaufmann M, Kiechle M, von Minckwitz G, et al. Demographic and psychosocial factors associated with risk perception for breast cancer. Oncol Rep. 2005;14(6):1605-13.

23. Census of India 2001. Available from: www.censusindia.govin/Census_Data_2001/India_at_glance/rural.aspx 2010.

24. Jayalekshmi P, Gangadharan P, Mani KS. Cancer in women in Kerala-a transition from a less-developed state. Asian PacJ Cancer Prev. 2006;7(2):186-90.

25. Hebert JR, Ghumare SS, Gupta PC. Stage at diagnosis and relative differences in breast and prostate cancer incidence in India: comparison with the United States. Asian Pac J Cancer Prev. 2006;7(4):547-55.

26. Pandey M, Thomas BC, SreeRekha P, Ramdas K, Ratheesan K, Parameswaran S, et al. Quality of life determinants in women with breast cancer undergoing treatment with curative intent. World J Surg Oncol. 2005;3:63.

27. Mahouri K, Dehghani Zahedani M, Zare S. Breast cancer risk factors in south of Islamic Republic of Iran: a case-control study. East Mediterr Health J. 2007;13(6):1265-73.

28. Sim X, Ali RA, Wedren S, Goh DL, Tan CS, Reilly M, et al. Ethnic differences in the time trend of female breast cancer incidence: Singapore, 1968-2002. BMC Cancer. 2006;6:261.

29. Do MH, Lee SS, Kim JY, Jung PJ, Lee MH. Fruits, vegetables, soy foods and breast cancer in pre- and postmenopausal Korean women: a case-control study. Int J Vitam Nutr Res. 2007; 77(2):130-41.

30. Ashing-Giwa KT, Padilla GV, Bohorquez DE, Tejero JS, Garcia M. Understanding the breast cancer experience of Latina women. $J$ Psychosoc Oncol. 2006;24(3):19-52.

31. Mousavi SM, Montazeri A, Mohagheghi MA, Jarrahi AM, Harirchi I, Najafi M, et al. Breast cancer in Iran: an epidemiological review. Breast J. 2007;13(4):383-91.

32. Paillocher N, Lacourtoisie SA, Fondrinier E, Catala L, Morand C, Boursier J, et al. [Infiltrating breast cancer in women younger than 25 years: 13 cases]. Presse Med. 2006;35(11 Pt 1):1618-24. 